\title{
LUZ EM MOVIMENTO
}

\section{Moving light}

\section{CUROTTO JUNIOR, JOSÉ ANTONIO I Especialista em Fotografia}

Universidade Norte do Paraná

juniorctto@gmail.com

\section{GHOMES, ROGÉRIO I Mestre em Design}

Universidade Estadual de Londrina

rogerioghomes@gmail.com

\section{Resumo}

Com foco no estudo da fotografia no cinema e suas principais características de cor e luz, a pesquisa baseia-se em teorias consagradas da área aliadas a estudos e definições de obras renomadas sobre o objeto em foco. A análise é focada em duas das principais características da fotografia do cinema, que são cor e luz.

Palavras-Chave: direção de fotografia; cinematografia; cinema; imagem

\section{Abstract}

With focus on the study of photography in film and its main characteristics of color and light, the research is based on established theories of allied studies and definitions of renowned works on the object in focus area. The analysis is focused on two major characteristics of film photography, which are color and light.

Key-words: cinematography; cinematography; film; image 


\section{INTRODUC̣̃̃O}

Essa pesquisa tem como objetivo primeiramente esclarecer a essência da direção de fotografia no cinema. Buscar as desigualdades entre a fotografia convencional e a fotografia em movimento. Através desta comparação temos como finalidade também esclarecer onde e como um diretor de fotografia no cinema consegue convencer e obter diferentes reações em um espectador através de sua arte.

Para um bom entendimento fundamentamos a direção de fotografia com dados obtidos em pesquisa sobre alguns dos principais profissionais da área, e em obras, buscando conceituações e a visão de quem trabalha com isso. Mostramos as divergências de terminologia, chegando a uma conceituação utilizada no restante do texto.

Por fim focamos em duas das principais características da fotografia no cinema: a luz e a cor. Acreditamos ser nessas áreas onde um diretor de fotografia mais usufrui do poder que tem em mãos. Há ainda um aprofundamento em cores complementares e um rápido esclarecimento de suas utilizações, principalmente na atualidade.

Vamos nos limitar aqui aos diretores de fotografia mais comprometidos com a imagem que produzem, ou seja, antes da linha do exagero de correções de cor excessivas, efeitos especiais desnecessários e afins. Limitamo-nos também a algumas cenas de cinco obras do cinema comercial, sendo O iluminado (1980), como representante de uma boa fotografia em um filme não atual; A ilha do medo (2009), como objeto representando um filme atual; A lista de Schindler (1993), analisado para casos específicos em nosso estudo de cores, especialmente sobre contrastes; o primeiro longa da trilogia O poderoso chefão (1972), retratando também contrastes como construtores de clima; e por fim $O$ resgate do soldado Ryan (1998), retratando o uso de cores complementares e diferenças de cores em sequências de climas e humores distintos.

\section{Um segundo congelado}

"[...] um homem sensato recordar-se-á que os olhos podem perturbarse de duas maneiras e por duas causas opostas: pela passagem da luz à obscuridade e pela passagem da obscuridade à luz." (PLATÃO, 1965, p.110).

Uma imagem é definitivamente capaz de acordar sentimentos, fazernos atentar a detalhes que jamais poderiam ser vistos na realidade, a olho nu. Podemos quase sentir o que um homem em uma fotografia sentia naquele 
segundo, ou senão, ao menos ter empatia com esse sentimento. É o que, podemos supor, Walter Benjamin tratou como inconsciente ótico:

\begin{abstract}
A Natureza que fala à câmara não é a mesma que fala ao olhar; é outra, especialmente porque substitui um espaço trabalhado conscientemente pelo homem, um espaço que ele percorre inconscientemente. Percebemos, em geral, o movimento de um homem que caminha, ainda que em grandes traços, mas nada percebemos de sua atitude na exata fração de segundo em que ele dá um passo. A fotografia nos mostra essa atitude [...]. Só a fotografia revela esse inconsciente ótico, como só a psicanálise revela o inconsciente pulsional. (BENJAMIN, 1994, p.94)
\end{abstract}

Mas nós iremos tratar aqui de cinematografia, ou seja, movimento. Porém este inconsciente também está aí. Ao menos é em revelá-lo no espectador que um diretor de fotografia encontra seu maior desafio: fazer isso aliado ao movimento. Já que, se há movimento, perdemos a chance de usar aquele "segundo congelado" da fotografia convencional a nosso favor.

Desde os irmãos Lumière e a história do cinema, grande parcela de suas técnicas, especificamente as que dizem respeito à fotografia, são consolidadas com o passar das décadas ao invés de descartadas com chegadas de novas tecnologias ou após experimentações. O que foge dos costumes fica difícil para um diretor de fotografia explicar e talvez por isso não se encontre tanto material sobre a fotografia no cinema quanto em outras áreas.

A fotografia é sempre considerada uma arte de artistas mudos. As entrevistas de fotógrafos são cheias de 'não sei explicar direito' e do inevitável "sou visual, não sei falar". Criou-se uma terra onde não é preciso ler. [...] A fotografia é a arte que menos se pensa por escrito. Livros considerados importantes em fotografia, quer dizer, de fotógrafos importantes, como Cartier-Bresson ou Rodchenko, são folheados em minutos. (MOURA, 1999, p.22).

\title{
Pinturas no escuro
}

Para início a análise desta pesquisa e para que haja melhor compreensão é necessária a apresentação dos conceitos básicos envolvidos. Como também pelo fato de haverem diferentes termos empregados para as funções responsáveis pela fotografia de um filme. 
A divergência está na utilização de dois termos diferentes para, basicamente, alguém que exerce em um filme a mesma função ou funções similares. Estes termos são diretor de fotografia (director of photography em inglês), cinematógrafo (cinematographer em inglês) ou ainda apenas fotógrafo, também usado no Brasil. Brown (2002), explica que o termo cinematografia vem do grego e significa escrever com movimento. Isso mostra, literalmente, o sentido deste campo, embora, ainda segundo Brown (2002), o termo cinematógrafo ainda está associado na mente de muitas pessoas com o processo de emulsão das películas, e por isso usa-se progressivamente o termo diretor de fotografia.

A única diferença entre usar o termo fotógrafo ou diretor de fotografia, como explicado por Moura, é que "diretor" demonstra mais respeito. E se um diretor de fotografia decide onde iluminar e em qual lugar ficará a câmera, ou seja, toma conta daquilo que constitui a fotografia de um filme, então ele está dirigindo. Já Storaro', muito conhecido por suas explicações artísticas e mais abstratas que técnicas, por exemplo, afirma: "Eu sou um cinematógrafo, não um diretor de fotografia.". Quando perguntado o motivo de negar o termo diretor de fotografia, ele completa:

Porque [...] um filme é como uma orquestra. Há apenas um condutor, um diretor. [...] fotografia, escrita com luz, é a expressão em imagens isoladas. Expressamo-nos em cinematografia: kino, movimento. [...] Em minha opinião, a expressão para fotografia é fotógrafo e, para cinematografia, cinematógrafo. É isso. (STORARO apud CINEMATOGRAPHER Style, 2006, tradução nossa).

Puramente, um filme são várias fotografias que, rodando em certa velocidade, dá a ilusão de movimento. O ritmo que o cinema impõe se torna um desafio e daí talvez venha o motivo de alguns negarem o termo diretor de fotografia, embora este seja amplamente usado.

Para essa pesquisa, adotamos então o conceito de Brown (2002, p.ix) sendo cinematografia como "mais que o mero ato da fotografia. É o processo de pegar ideias, ações, contexto emocional, tom e outras formas de comunicação não verbal e traduzi-las em termos visuais.". Sendo assim a cinematografia a arte e a ferramenta do diretor de fotografia.

Gordon Willis é diretor de fotografia, conhecido como

$1 \quad$ Vittorio Storaro é diretor de fotografia. Conhecido por seus trabalhos em $\mathrm{O}$ último tango em Paris; Apocalypse now; e também por sua parceria com Francis Ford Coppola. 
"Príncipe da escuridão" por seu estilo de fotografia com altos contrastes, onde várias vezes um dos lados da face dos atores está obscuro. Tem reconhecido trabalho por ter dirigido, entre tantos, os filmes da trilogia O Poderoso Chefão.

Se dirigir a fotografia de um filme fosse pura e literalmente a função de apenas dirigi-la, o resultado seria um filme desconexo ou ainda haveriam inúmeros conflitos ideológicos entre o diretor e o diretor de fotografia. Esse último deve compreender a visão do diretor, aliá-la a sua própria visão e uni-las com os elementos da fotografia, ou seja, o diretor de fotografia deve conhecer tantos os aspectos técnicos quanto os artísticos e mais abstratos para poder desempenhar bem sua função. Ir de um extremo ao outro é a única maneira de interpretar um conceito visual e fazê-lo ser interpretado pelo espectador posteriormente de forma homogênea. Homogênea, dizemos no sentido do filme ter essa homogeneidade visual, de se completar em seus aspectos. O diretor de fotografia mostra como é a história, mostra a sua versão visual dela. Gordon

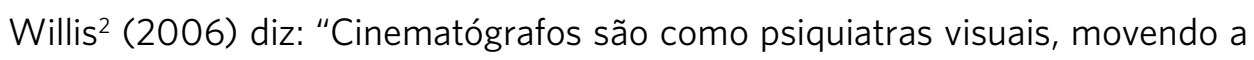
audiência daqui para lá, e ali. Pintando imagens no escuro.".

As boas inovações no cinema, mais especificamente na fotografia dos filmes, estão na sutileza e não em mudanças abruptas de técnicas desenvolvidas ao longo dos cem últimos anos. Uma regra pode ser quebrada e um truque pode ser usado:

\begin{abstract}
Somente a experiência ensinará o fotógrafo e o editor quando e como usar truques. O segredo de um truque eficaz está em saber como fazer mudanças sem que o público perceba. O único crime ao usar truques é ser pego. [...] o técnico experiente sabe até que ponto o truque pode ser empregado antes que o espectador perceba a mudança. (MASCELLI, 2010, p.15).
\end{abstract}

Essa sutileza geralmente está nas peculiaridades de um diretor de fotografia, nos seus improvisos, suas manias, enfim, em sua veia artística, que junto com sua experiência o mostrará quando usar suas facetas e o que o espectador sentirá. É justamente na arte tão inexplicável que se encontra a grande diferença. Com as novas tecnologias ainda há um apelo bizarro de se tentar surpreender o espectador inflando filmes com efeitos muitas vezes

2 Gordon Willis é diretor de fotografia, conhecido como "Príncipe da escuridão" por seu estilo de fotografia com altos contrastes, onde várias vezes um dos lados da face dos atores está obscuro. Tem reconhecido trabalho por ter dirigido, entre tantos, os filmes da trilogia O Poderoso Chefão. 
desnecessários. Não estamos criticando a ficção científica, por exemplo, que depende de uma pós-produção com estes recursos, somente expondo os malefícios do uso irresponsável da tecnologia. Há uma linha muito tênue entre um diretor de fotografia usar suas técnicas e seus instintos e criar uma imagem o mais possível pronta durante a produção ou deixar o máximo que puder para o computador, criando uma imagem cada vez mais virtual. A imagem sobrecarregada deixa de ser orgânica.

Programas cada vez mais potentes e sofisticados permitem criar universos virtuais, que podem se apresentar como tais, mas também fazer trucagens como qualquer imagem aparentemente "real". Qualquer imagem passou a ser manipulável e pode perturbar a distinção entre "real" e virtual. (JOLY, 1996, p.26).

Porém, vamos nos conter aos adeptos da "realidade". A fotografia de um filme, justamente por ser de um filme e por ser uma fotografia, está fadada a não ser a realidade, mas uma representação dela, de acordo com Joly (1994, p.39): "Se ela parece é porque ela não é a própria coisa, sua função, portanto, é evocar, querer dizer outra coisa que não ela própria.". A tarefa de um diretor de fotografia, obviamente, não é a de representar a realidade o mais fielmente que puder, principalmente no cinema que visa o lucro. Porém a imagem registrada no filme, ou no arquivo, se falarmos dos formatos digitais, é a mais próxima da realidade vista:

\begin{abstract}
Na maioria das vezes, as imagens registradas assemelhamse ao que representam. A fotografia, o vídeo, o filme são considerados imagens perfeitamente semelhantes, ícones puros, ainda mais confiáveis porque são registros feitos, como vimos, a partir de ondas emitidas pelas próprias coisas. (JOLY, 1996, p.40).
\end{abstract}

Com essa afirmação de Joly podemos confirmar então que essas ondas emitidas pelas coisas e captadas diretamente na câmera são a forma mais fiel possível de se representar a realidade como ela foi vista, ainda que essa realidade fora forjada para contar uma história fictícia. Aí está a diferença mais uma vez: O diretor de fotografia que atinge ali, na hora da gravação, a representação desejada daquela realidade sem ter que sofrer ajustes drásticos posteriormente.

Agora podemos pensar em como o diretor de fotografia traduz essa realidade da história a ser contada em um filme para o filme em si e atinge o efeito esperado no espectador. Embora alguns diretores de fotografia tentem 
desmistificar uma escolha de cores predominantes, luzes ou câmeras, é fato que seu subconsciente age mesmo nessas horas. E o espectador que assiste a obra final se deixa levar por essas escolhas sem ao menos percebê-las analiticamente. Sua subjetividade, se atingida, fará uma cena se tornar inesquecível ou não para ele. Mas, com certeza, a fotografia de um filme atinge somente uma parcela de um todo que é necessário para se gerar um clímax ideal. E é justamente por ser tão subjetivo o efeito que ele pode ser um dos maiores contribuintes em uma cena

As ferramentas de um diretor de fotografia são várias. Bem como existem várias listas e classificações sobre as coisas mais importantes na fotografia de um filme. Mascelli, por exemplo, criou a lista d'Os cinco Cs da cinematografia ${ }^{3}$. Claro que na década de sessenta não havia tanta especificidade entre os cargos da equipe de um filme. Porém sua lista tão consagrada contém os fundamentos mais que necessários para qualquer diretor de fotografia.

O que temos como foco agora não é, então, listar as premissas da direção de fotografia, mas descobrir quais são os segredos para prender o espectador e atingi-lo da maneira desejada tendo em vista, como falamos, o movimento do cinema. Se perdemos aquela estática, o segundo congelado da fotografia convencional, ganhamos também com o movimento. Independente da técnica por trás deste, certamente observaremos seus benefícios posteriormente.

\section{Luz e cor}

A luz é a fonte da maior parte do trabalho de um diretor de fotografia. Não é sem motivos que a tradução literal de fotografia "pintando no escuro" é tão falada no meio. A luz é o controle primário na construção da fotografia de uma cena. É ela quem determina a base do clima através de sua aplicação. Aqui vamos estudar tanto ela em si como características a ela associadas.

Por isso, para primeiro lugar destinamos o estudo das cores e da luz. Principalmente por, ao vermos ao final da análise, exercerem tanta importância nas mãos do diretor de fotografia. É claro que a cor está, nos âmbitos da fotografia, associada com a iluminação. Não vamos nos aprofundar aqui em direção de arte.

A luz é mediação. Os objetos do mundo aguardam inertes e latentes a sua manifestação, que só será possível, quando

3 Em 1965, Joseph V. Mascelli escreveu Os cinco Cs da cinematografia. O livro se tornou referência entre diretores de fotografia em todo mundo até os dias de hoje, sendo considerado uma Bíblia da área. 
levados por feixes luminosos até os nossos olhos. [...] [a visão] é talvez o sentido que mais faz vibrar o ser humano e o faz pensar, gozar e desfrutar as coisas do mundo que o rodeia. (FARINA; PEREZ; BASTOS, 2006, p.27).

Por ter tanta influência no resultado em um espectador, as cores se tornaram uma grande ferramenta aliada à iluminação para diretores de fotografia. O uso de diferentes tonalidades deixou de ser simples adorno, e a iluminação, portanto, que já era algo fundamental, passou a ter usos progressivos como construtores de clímax.

Mas antes de falarmos da cor, é preciso falar da luz e uma de suas principais características: o contraste. Se fossemos analisar um filme preto e branco, por exemplo, esse seria nosso foco principal sem dúvida alguma. Como no caso do filme A lista de Schindler (1993), de Spielberg e direção de fotografia ${ }^{4}$ de Kaminski ${ }^{5}$, rodado em sua maioria em película P/B. O que, de acordo com Kaminski, daria atemporalidade ao filme.

Vamos aproveitar então $A$ lista de Schindler para uma análise do uso do contraste pelo diretor de fotografia e observar quais impactos temos como resultados nas diferentes cenas.

Figura 1 - O contraste entre os planos

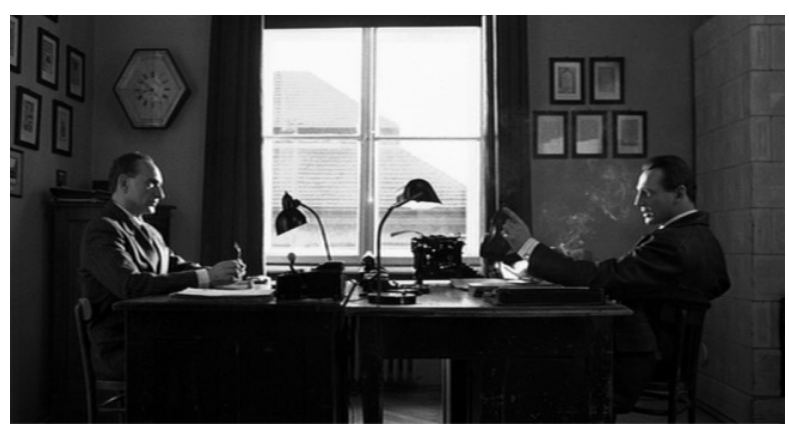

Fonte: A lista de Schindler (1993).

A fotografia de um filme preto e branco deve ter cuidados especiais para que não se perca a profundidade e tudo acabe se misturando: "O contraste por luz e tom baseia-se nas sucessivas oposições claro-escuro. O efeito da luz, reproduzindo-se sobre os objetos, cria a noção de volume - com a presença ou ausência de cor." (GOMES FILHO, 2004, p.64). A diferença tonal entre as roupas, o cenário e a pele deve ser evidenciada para que no preto e branco se mostrem como coisas a parte.

$4 \quad$ A fotografia de A lista de Schindler foi premiada com uma das sete estatuetas do Oscar que o filme recebeu.

5 Janusz Kaminski é diretor de fotografia. Conhecido por seus trabalhos em 0 resgate do soldado Ryan; Minority Report; Prenda-me se for capaz, entre outros. 
A cena da figura 1 demonstra bem o uso do contraste. Os atores em primeiro plano estão evidenciados e distintos do segundo plano, que é a parede ao fundo e a janela. A luz que ataca o rosto de ambos e a mesa delineiam essa separação. Na verdade, neste caso, provavelmente a luz deva ter sido reforçada com dois pontos externos voltados para o rosto de cada um dos atores. Este ataque vindo da janela se mostra ainda mais eficaz ao ponto em que podemos observar os detalhes da fumaça do cigarro à direita. A luz de preenchimento, bem como uma parede mais clara e destoante ao figurino e mesa escuros, intensifica a profundidade da cena. Mesmo não sendo parte da iluminação vale adicionar o fato de que a escolha de uma lente grande angular (como podemos observar pelas extremidades levemente distorcidas do quadro) dá a sensação de movimento e também contribui para a tridimensionalidade da cena. Neste caso, a cena apenas sugere movimento, pois o filme foi praticamente todo rodado com lentes fixas e assim o efeito da fotografia estática tradicional está presente.

O contraste também tem efeito dramatizador. É o conhecido caso da luz de ataque sozinha versus a luz de ataque com a luz de preenchimento. Um contraste evidenciado com sombras duras e preto intenso, com menos meiostons, pode mostrar algo misterioso, intrigante ou obscuro. É o também chamado chiaroscuro:

\begin{abstract}
Italiano para luz (chiara) e sombra (scouro, mesmo raiz do Latim para obscuro), chiaroscuro, ou graduações de luz e escuridão [...], estabelecem a percepção de profundidade e criam foco visual. À partir do momento em que lidar com a luz é um de nossos maiores trabalhos, essa é uma importante consideração em nosso trabalho. (BROWN, 2002, p.37, tradução nossa)
\end{abstract}

O chiaroscuro, naturalmente como várias outras características e técnicas da fotografia, vêm da pintura. A técnica do contraste dramático era muito usada pelo pintor barroco Caravaggio, como podemos ver na figura 2 .

Figura 2 - David com a cabeça de Golias (1605), por Caravaggio

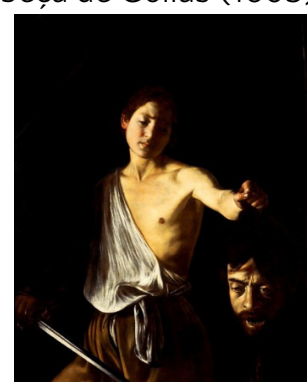

Fonte: Manguel (2001, p.292) 
A cena da figura 3 mostra um bom exemplo, também d'A lista de Schindler, do uso do chiaroscuro.

Figura 3 - O uso do chiaroscuro

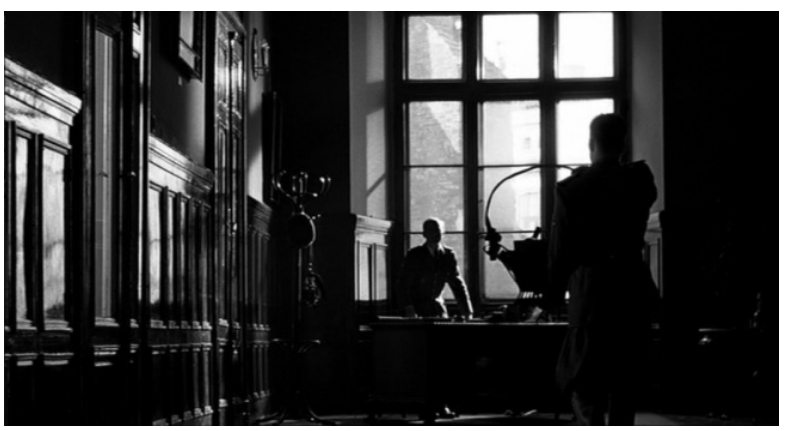

Fonte: A lista de Schindler (1993).

Nesta cena, o contraste é formado pela escuridão total e a luz apenas delineia as silhuetas e a parede lateral, com poucos meios-tons. A cena ganha em dramaticidade e mistério, fazendo o espectador se perguntar o que está por vir, mesmo que subconscientemente. $O$ contraste mostra em suas técnicas, principalmente vistas em preto e branco, que é um grande elemento para o clímax de uma sequência, seja ela dramática ou na evolução da tensão.

Também na tela de Caravaggio (figura 2), a dramaticidade é enorme pelo seu contraste. Nada mais está em foco senão simplesmente a cabeça de Golias agarrada pelos cabelos entre os dedos de David e arma em punhos. As expressões ganham destaque e inegavelmente causam apreensão a qualquer observador.

Com este básico do contraste, o diretor de fotografia inicia então a construção do clima. A escolha do filme A lista de Schindler não foi aleatória. O preto e branco nos ajuda a evidenciar e entender melhor o contraste e o uso que o diretor de fotografia faz dele. Mas agora vamos observar a aplicação também da cor.

Provavelmente entre os melhores exemplos que podemos utilizar para analisar o uso de ataques fortes e altos contrastes é a trilogia O Poderoso Chefão, com fotografia do já citado Gordon Willis. Selecionamos alguns quadros do primeiro filme da série. E muitos deles se mostram também ótimos exemplos de chiaroscuro.

As clássicas cenas do escritório de Don Corleone (Marlon Brando) são o exemplo eternizado do motivo de Willis ser chamado de "príncipe da escuridão". Como podemos ver na figura 4, a cena é tomada por um ataque vindo da janela, passando por suas persianas, completada por uma luz de ataque no interior da 
sala com gel avermelhado e os abajures complementares.

Figura 4 - Fotografia d'O Poderoso Chefão

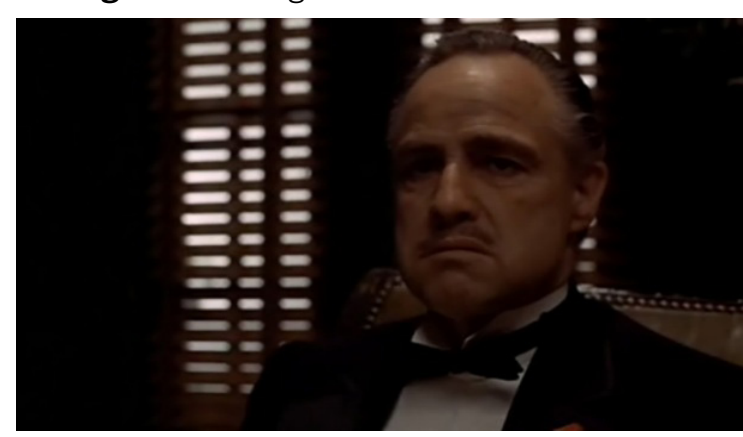

Fonte: O Poderoso Chefão (1972).

As luzes de ataque no interior foram posicionadas acima, apontadas para baixo. Simulam uma iluminação padrão de luzes incandescentes em ambientes fechados e não são tão fortes, o que pode parecer ainda luz de preenchimento devido ao toque tão natural que fornecem. É relevante ainda ressaltar a bela composição do quadro, valorizando o olhar do personagem posicionado em um dos pontos de ouro.

O efeito dramático deste tipo de fotografia é com certeza impulsionado. O espectador é colocado em um ambiente onde as sombras parecem cobrir qualquer pista sobre quaisquer que sejam suas dúvidas.

Figura 5 - Fotografia d'O Poderoso Chefão

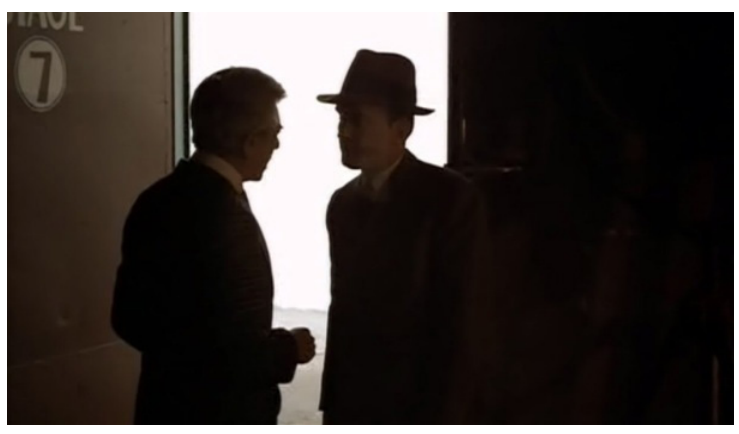

Fonte: O Poderoso Chefão (1972).

Algumas vezes o espectador ainda fica na dúvida de onde os personagens estão. Na figura 5 temos um clima também envolvendo questionamentos, e há ainda, mas não menos importante, o fator extra que o ataque natural do segundo plano e essa superexposição dão ao sentido e a relevância do próprio diálogo entre os personagens, que ganha maior expressão e certo sentido de segredo.

Assim se construiu O Poderoso Chefão, com seus interiores repletos de 
obscuridade, sombras, contrastes e silhuetas. Podemos perceber com estes e os exemplos anteriores, quão importante é o contraste para o diretor de fotografia. Podendo ele em si, praticamente sozinho, ditar o clima de um filme e escrever seu sentido visual.

Outro elemento que ganha cada vez mais uma importância específica e técnicas peculiares é a cor. Obviamente que sempre haverão aberrações e experimentações exageradas, mas vamos analisar como um diretor de fotografia pode usar a cor para contar uma história através do seu uso.

As cores tem sua utilização para diversos fins. Seu uso no cinema está diretamente ligado ao lado psicológico de cada espectador e sabendo-se disso, os diretores de fotografia as usam a seu favor para chegar ao resultado desejado e criar o clima de um filme.

O uso mais intenso e mais específico das cores vem crescendo junto com a tecnologia e o próprio estudo aprofundado da área. Em obras mais antigas não havia tanta preocupação em usar as cores para destacar um primeiro plano por exemplo. Os usos mais claros das cores para interferirem no clima do filme eram o básico azul para os lugares frios e os amarelos, laranjas e vermelhos para lugares quentes. E estamos falando aqui da temperatura psicologicamente associada a cor, e não a temperatura física da luz e cada cor, que no caso seria inversa. De fato, o básico quente/frio e as suas cores associadas podem ser comprovadas de acordo com suas significações, como é possível constatar no clássico A psicodinâmica das cores em comunicação. De acordo com Farina, Perez e Bastos (2006), o vermelho tem associação de fraternidade, acolhimento e calor, por exemplo. Enquanto o azul tem associações de frio e gelo.

No filme O Resgate do Soldado Ryan, com fotografia de Kaminski, em uma de suas tantas parcerias com Spielberg, podemos analisar as diferenças de clima e cor de acordo com algumas cenas.

Figura 6 - Diferentes cores em O Resgate do Soldado Ryan
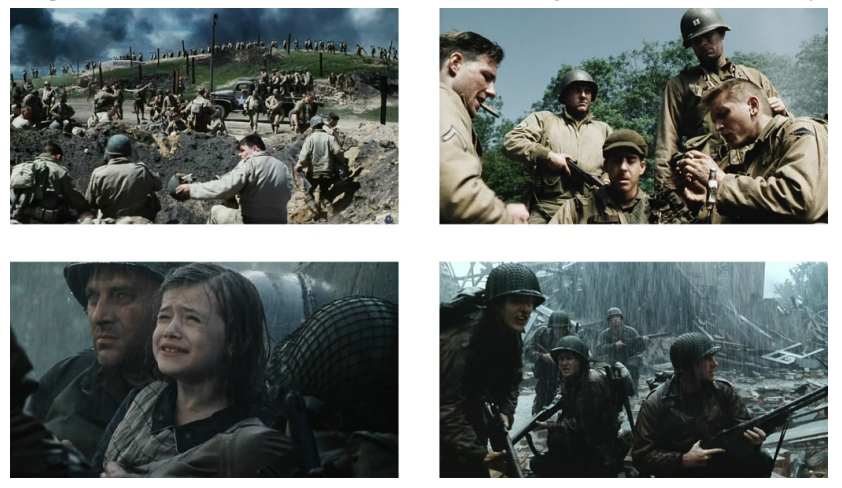

Fonte: O Resgate do Soldado Ryan (1998). 
Na figura 6 temos quatro quadros. Podemos ver que, nos dois superiores, temos cores quentes e mais saturadas, enquanto nos dois inferiores vemos 0 oposto, cores frias e baixa saturação.

O filme em si conta com uma saturação menor, o que não se mostrava como tendência tão grande quanto nos dias de hoje. É uma escolha natural para filmes de época e guerra. Porém em cenas de maior tensão temos uma saturação ainda mais baixa. Os dois quadros inferiores mostram a sequência em que os soldados protegem uma menina de um franco atirador. Já nas cenas dos acampamentos aliados e horas de triunfo vemos mais cores, como os quadros superiores, da vencida batalha de invasão da praia de Omaha e de uma cena em um acampamento das forças aliadas. As diferenças, portanto, mostrando o poder das cores influenciando reações e sentimentos do espectador.

Atualmente uma grande artimanha dos diretores de fotografia é o uso de cores complementares em segundo plano para evidenciar um primeiro plano. Isso é ainda mais reforçado com a pós-produção.

Em A ilha do medo (2009) de Scorsese e direção de fotografia de Richardson ${ }^{6}$, é interessante observarmos as diferenças entre as memórias da personagem de Leonardo Di Caprio e a linha de acontecimentos normais.

Figura 7 - As cores em cenas externas

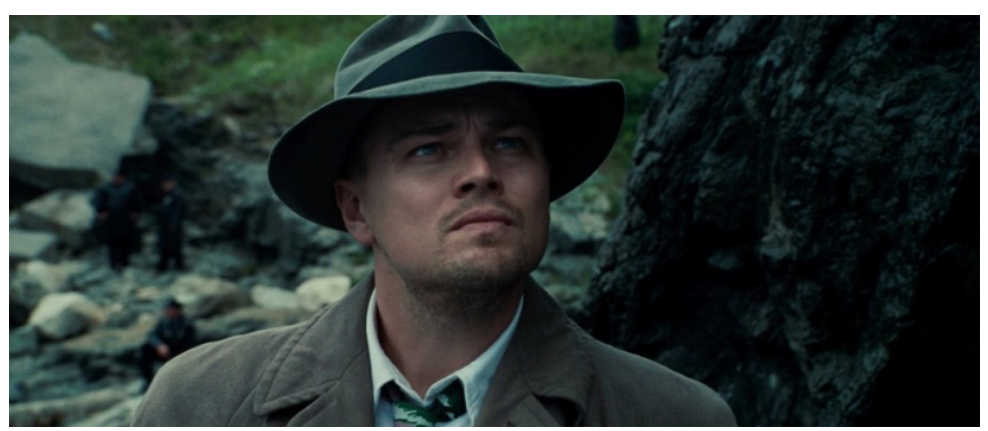

Fonte: A ilha do medo (2009).

Podemos ver na figura 7 uma cena externa de A ilha do medo. É possível observar o destaque que 0 ator ganha com a predominância de tons azuis, verdes e cinzas ao fundo e em sua própria roupa. A saturação em geral do filme é mais baixa, seguindo tendências de Hollywood. Porém sem exageros, para um filme de época podemos afirmar que é uma boa alternativa, principalmente pela direção de arte do filme que, em conjunto com a fotografia criaram um clima vintage.

6 Robert Richardson é diretor de fotografia, conhecido por seus trabalhos em Kill Bill (1 e 2); Bastardos inglórios; O aviador; Platoon, entre outros. 
A predominância dos tons de azul, verde e cinza em segundos planos não é sem motivos. Se observarmos um círculo de harmonização das cores, iremos constatar que as cores complementares para tons de pele, serão imediatamente seus opostos, que, consequentemente, serão cores entre verde, azul e até roxo. O que pode então parecer um clichê do cinema é apenas um método que provém de anos de estudo desde Newton, Goethe e outros estudiosos das cores. Este método está também muito ligado ainda aos diretores de arte, cenógrafos e figurinistas.

O que se atinge pelas cores complementares é então um foco maior em nosso primeiro plano. No caso da cena, a personagem de Leonardo Di Caprio. Esta é possivelmente uma das principais atuações das cores para um diretor de fotografia. O modo como ele pode controlar isso vai desde a iluminação, o uso de géis, filtros e até a pós-produção.

Na cena da figura 8 temos uma representação das sequências das lembranças da personagem de Di Caprio. Elas têm saturação mais elevada, cores vibrantes e brancos estourados, indo um pouco a contramão das overdoses da indústria dos últimos anos.

Figura 8 - Cores vibrantes em A ilha do medo

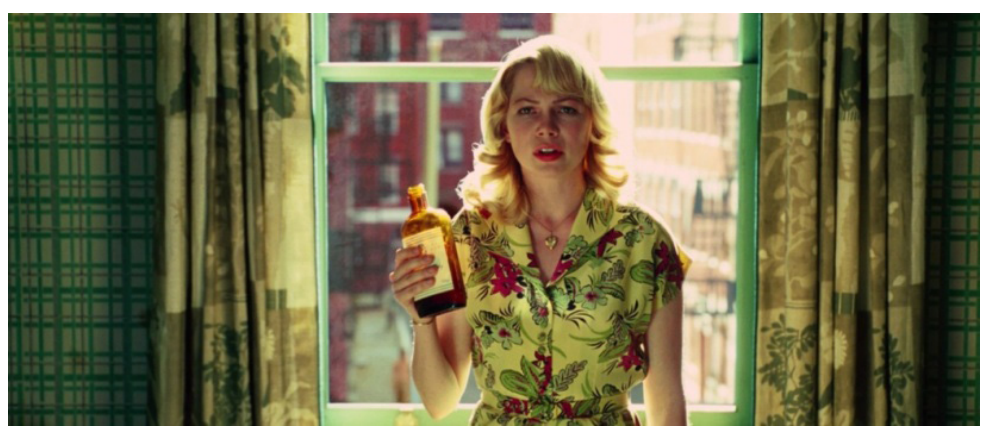

Fonte: A ilha do medo (2009).

Richardson, contando com o respaldo de um departamento de arte muito competente, criou uma sequência para as lembranças entorpecidas com uma saturação e um contraste que fazem o espectador sentir-se agoniado. As cores estampam os detalhes e os escancaram. Neste caso temos um ataque vindo da janela e estourando o branco, fazendo a silhueta da personagem se fundir em certos pontos com o fundo e as luzes de preenchimento clareando e exaltando cada diferente tom da roupa e do cenário. Também devemos considerar o provável uso de filtros para se atingir este resultado.

Pelo branco da janela vemos que também houve o uso das cores complementares, já que ele é mais esverdeado que o comum, o que é um provável resultado de gel nas luzes de preenchimento do fundo. 


\section{Cores complementares}

O círculo criado por Goethe é a base para as cores complementares. De acordo com Pedrosa (2006, p.118): "Para Goethe, a mais bela harmonia das cores encontrava-se na representação gráfica do círculo cromático. No círculo criado por ele cada cor está diametralmente oposta à sua complementar." O círculo de Goethe (figura 9) foi utilizado para a construção de círculos de harmonização da cor, ferramentas para construção de esquemas de cor por diretores de fotografia, bem como profissionais de outras áreas.

\section{Figura 9 - O círculo de Goethe}

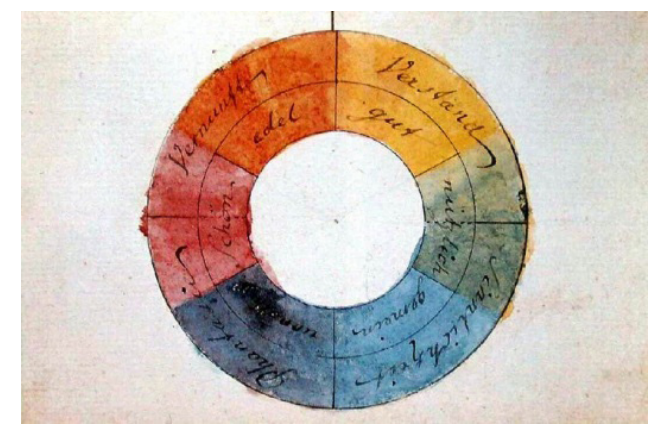

Fonte: DigitalSherpa (2014)

Na figura 10 temos outro quadro do filme A ilha do medo:

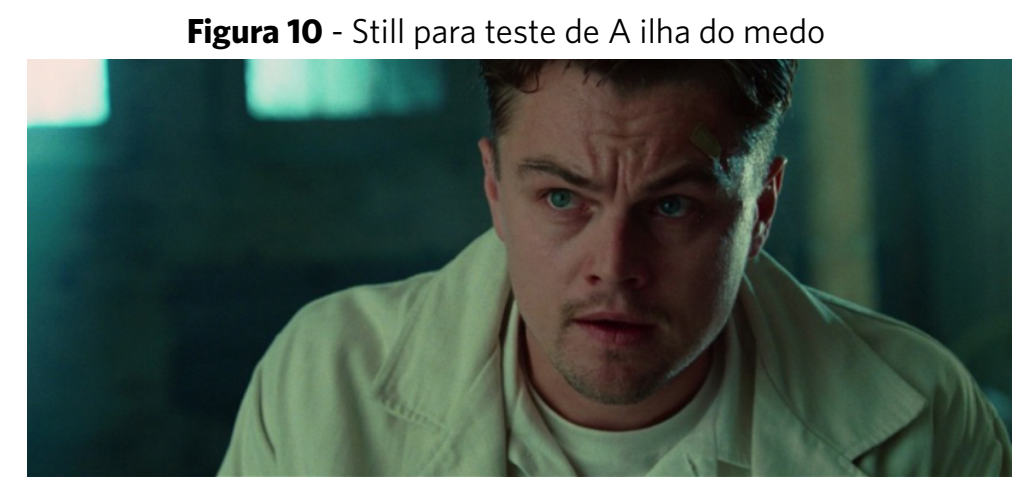

Fonte: A ilha do medo (2009).

Em um software de edição de imagens detectamos que a cor do rosto da personagem (lado esquerdo, mais claro) é formada por tons próximos de \#766156 (em código hexadecimal). Em uma ferramenta de cores complementares, inserimos o código hexadecimal na cor base e o resultado foram as cores \# 67C2BE e \# 567675 como nossas complementares. Tons próximos aos do segundo plano de nossa cena. O que justifica mais uma vez a efetividade do uso da técnica. A figura 11, capturada diretamente da ferramenta, mostra o resultado obtido: 
Figura 11 - Resultado de cores complementares no software

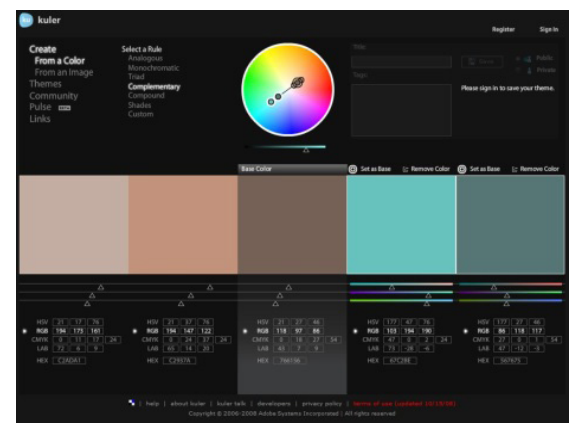

Podemos comparar o resultado com o círculo de Goethe da figura 12 e rapidamente é fácil observar a veracidade deste resultado, sendo o ponto da cor da pele entre o amarelo e o vermelho e suas complementares diametralmente opostas entre o azul e o verde.

Na figura 12 temos um quadro do filme O Resgate do Soldado Ryan. O filme, produzido em 1998, contou com a técnica, que na época era usada mais timidamente, e obteve um excelente resultado.

Figura 12 - Cores complementares em O Resgate do Soldado Ryan

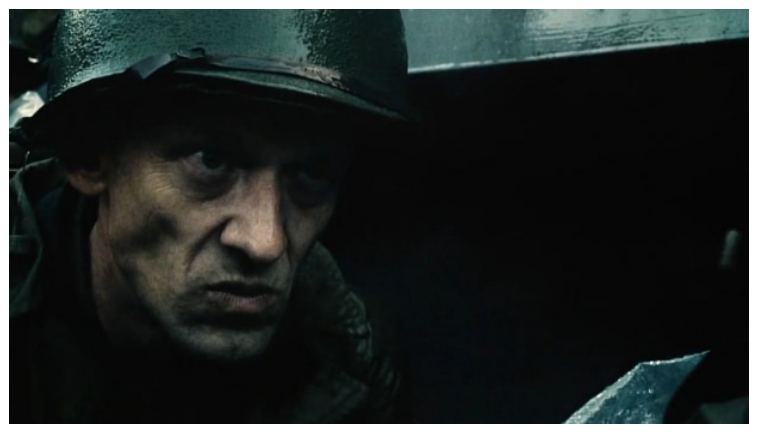

Fonte: O Resgate do Soldado Ryan (1998).

Verificamos no rosto do personagem a cor \#B09583. No software, obtivemos como cores complementares \#366163 e \#83AEBO, como podemos ver na figura 13.

Figura 13- Resultado de cores no software

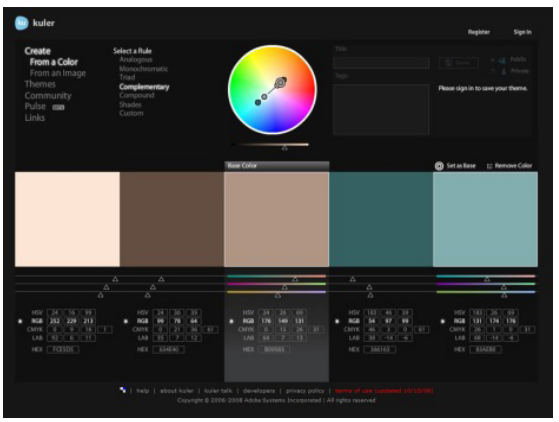


Assim as cores complementares se mostram um artifício muito poderoso para a fotografia no cinema. O diretor de fotografia pode ousar mais com essa possibilidade, mas sempre lembrar-se também dos limites do exagera. A ilha do medo acaba se mostrando um bom exemplo de equilibro contrapondo boas composições com o uso das cores complementares. No filme nem sempre o segundo plano terá os tais tons verdes ou azuis, o diretor de fotografia não pode e nem deve se tornar dependente de um artifício, pois, como vimos, ele tem vários a sua disposição. Em O resgate do soldado Ryan, o uso é facilmente observado principalmente nas primeiras cenas, no desembarque na praia de Omaha e também em cenas de ação, ou seja, as cores complementares estrategicamente utilizadas como instrumento de construção de clima, que no caso é a tensão, adrenalina e o receio dos soldados.

\section{CONSIDERAC̣ÕES FINAIS}

Essa pesquisa traçou os princípios mais fundamentais da direção de fotografia no cinema aliando a teoria com os fundamentos artísticos, históricos e a técnica. Como resultado, podemos concluir que, apesar de haver uma clara diferença entre a fotografia convencional e a fotografia do cinema, há ainda muitas semelhanças. Com nosso foco em aspectos de cor e luz foi possível encontrar pontos onde um diretor de fotografia tem o ápice de sua arte. Foi possível também constatar a evolução do uso das cores complementares com o tempo.

As obras analisadas nesta pesquisa foram comerciais, e justamente por se tratarem de ficção, ficaria vago tentar justificá-las como espelhos da realidade. O real de um filme de ficção pode tentar ser tão real quanto a vida ou tentar sublinhar e exagerar certos aspectos para que aquilo se torne evidente e leve o espectador mais facilmente à interpretação e a reflexão daquela obra. Qualquer que seja a tentativa, que não o exagero grotesco, terá seu crédito artístico. Resultamos que a fotografia no cinema contém sempre certo exagero, mas um exagero bom, escancarando mais a realidade daquela obra ao espectador. Creditamos, por fim, os diretores de fotografia por exagerarem tão cautelosamente e criarem ambientes fantásticos, fazendo o próprio espectador acreditar na existência dessa realidade e fantasiar nela. Afinal, a ficção está aí para isso. É justamente onde observamos estar a essência do trabalho de um bom diretor de fotografia.

Deixamos ainda aberta a possibilidade de extensão desta pesquisa com o levantamento hipotético de o aprofundamento na característica de movimento da fotografia do cinema nos mostrar ainda mais características que enalteçam 
essa arte. Após analisados os filmes A lista de Schindler e O resgate do soldado Ryan e percebida a relação com o expressionismo alemão, ainda estimulamos o estudo dessa influência em diretores como Spielberg e seu parceiro diretor de fotografia Kaminski.

\section{REFERÊNCIAS}

A ILHA do medo. Direção de Martin Scorsese. Produção de Martin Scorsese, Bradley J. Fischer, Mike Medavoy, Arnold W. Messer. EUA: Paramount pictures, 2009. 1 DVD.

A LISTA de Schindler. Direção de Steven Spielberg. Produção de Steven Spielberg, Gerald R. Molen, Branko Lustig. EUA: Universal pictures, 1993. 2 DVDs.

BENJAMIN, Walter. Magia e técnica, arte e política: ensaios sobre literatura e história da cultura. Tradução de Sérgio Paulo. 7. ed. São Paulo: Brasiliense, 1994.

BROWN, Blain. Cinematography: theory and practice. Burlington: Focal Press, 2002.

CINEMATOGRAPHER style. Direção de Jon Fauer. Produção de Jon Fauer. EUA: T-stop Productions, 2006. 1 DVD.

DIGITALSHERPA. O círculo de Goethe. Disponível em:<http://www. digitalsherpa.com/ blog/designsherpa/>. Acesso em: 10 jan. 2014.

FARINA, Modesto; PEREZ, Clotilde; BASTOS, Dorinho. Psicodinâmica das cores em comunicação. São Paulo: Blucher, 2006.

GOMES FILHO, João. Gestalt do objeto: sistema de leitura visual da forma. 6. ed. São Paulo: Escrituras Editora, 2004.

JOLY, Martine. Introdução à análise da imagem. Campinas: Papirus, 1996.

MANGUEL, Alberto. Lendo imagens: uma história de amor e ódio. Tradução de Rubens Figueiredo, Rosaura Eichemberg, Cláudia Strauch. São Paulo: Companhia das letras, 2001.

MASCELLI, Joseph V. Os cinco Cs da cinematografia: ténicas de filmagem. Tradução de Janaína Marcoantônio. São Paulo: Summus, 2010. 
MOURA, Edgar Peixoto de. 50 anos luz, câmera e ação. São Paulo: SENAC, 1999.

O PODEROSO chefão. Direção de Francis Ford Coppola. Produção de Ian Bryce, Mark Gordon, Gary Levinsohn, Steven Spielberg. EUA: Paramount pictures, 1972.1 DVD.

O RESGATE do soldado Ryan. Direção de Steven Spielberg. Produção de Albert S. Ruddy. EUA: Paramount pictures, 1998.1 DVD.

PEDROSA, Israel. O universo da cor. Rio de Janeiro: SENAC, 2006.

PLATÃO. A República. São Paulo: Difusão Européia do livro, 1965. v. 2. 